\title{
Atividades com o Tangram no ensino remoto: uma abordagem envolvendo o Desenho Universal para a aprendizagem
}

\author{
Isaura Aparecida Torse de Almeida (D) Dandara Lorrayne do Nascimento (D)
}

\begin{abstract}
Resumo
Em virtude do panorama educacional ocasionado pela pandemia do novo Coronavírus, no qual o processo de ensino e aprendizagem acontece de maneira remota com a contribuição das tecnologias, neste artigo apresentamos uma proposta de atividades com o jogo Tangram com o intuito de auxiliar os professores na prática pedagógica. Este estudo constitui-se de uma pesquisa qualitativa com 57 professores de diversos níveis de ensino sobre suas percepções em relação ao Desenho Universal para a Aprendizagem (DUA). Observamos que 82,5\% dos professores não conheciam o processo de ensino-aprendizagem com base no Desenho Universal para a Aprendizagem, mesmo sendo este um instrumento metodológico facilitador da aprendizagem. Com base nesse resultado, elaboramos um livro digital interativo a fim de favorecer o processo de ensino e respeitar os ritmos e estilos de aprendizagem dos estudantes.
\end{abstract}

Palavras-chave: Ensino Remoto; DUA; Tangram; Geogebra.

\begin{abstract}
In view of the educational panorama caused by the new Coronavirus pandemic, where the teaching and learning process takes place remotely with the help of technologies, in this article we present a proposal of activities with the Tangram game in order to assist teachers in pedagogical practice - To carry out this work, we carried out a qualitative research with 57 teachers from different levels of education on their perceptions about Universal Design for Learning (DUA). We observed that $82.5 \%$ of teachers do not know the teaching-learning process based on Universal Design for Learning, even though this is a methodological instrument that facilitates learning. Based on this result, we created an interactive digital book in order to favor the teaching process and respect the students' learning rhythms and styles.
\end{abstract}

Keywords: Remote Teaching; DUA; Tangram; Geogebra.

\section{Introdução}

Mais de um milhão de alunos em todo o mundo estão afastados da escola em virtude da pandemia causada pelo novo Coronavírus (Covid-19) [26]. Diversos países, incluindo o Brasil, optam por transferir as aulas para plataformas on-line, e, em consequência desta situação atípica, professores 
enfrentam desafios na prática pedagógica, pois necessitam ajustar os conteúdos de acordo com os estilos e ritmos de aprendizagem dos alunos.

A prática pedagógica nesta nova situação requer investigação, planejamento e preparação de atividades que permitam aos alunos construírem seus conhecimentos, e isso pode se tornar difícil de ser realizado a distância, pois são necessárias adaptações curriculares, metodologias e materiais diversificados para que todos os alunos tenham a mesma oportunidade no processo ensino e aprendizagem na perspectiva da "não presença" do professor.

Outro fato a ser considerado é em relação à diversidade. O conceito de diversidade é inerente à educação inclusiva e remete ao entendimento de que todos os alunos apresentam certas necessidades educacionais individuais que podem ocorrer em momentos diferentes durante a escolarização.

Ressaltamos que “[...] a inclusão implica uma mudança de perspectiva educacional, pois não se limita aos alunos com deficiência e aos que apresentam dificuldade em aprender, mas a todos os demais, para que obtenham sucesso na corrente educativa geral" [9, p. 24].

Pelo acima exposto e refletindo sobre o ensino da matemática, elaboramos uma sequência de atividades on-line com o jogo Tangram, com base no Desenho Universal para a Aprendizagem (DUA), com o objetivo de contribuir com propostas educacionais em tempos de pandemia.

Além disso, foi realizado um estudo com 57 professores a fim de refletir sobre o modelo pedagógico do Desenho Universal para a Aprendizagem (DUA).

\section{Fundamentos Teóricos}

\subsection{EAD x Ensino Remoto: Qual o papel do professor?}

A história da Educação a Distância (EaD) no Brasil teve início em 1904, quando o Jornal do Brasil registrou, na seção de classificados, o primeiro anúncio que oferecia profissionalização por correspondência para datilógrafo [1]. Essa modalidade de ensino foi regulamentada pelo artigo 80 da Lei 9394/96 e tem como pressuposto que o ensino se desenvolve de forma assíncrona, ou seja, professor e aluno não participam do processo de ensino e aprendizagem ao mesmo tempo [3].

Já o ensino remoto é um formato recente, idealizado no contexto da pandemia do novo Coronavírus. No ensino remoto são utilizadas plataformas síncronas (ao mesmo tempo), assíncronas e diferentes atividades que podem ou não englobar o acesso à internet.

Dessa forma, segundo as orientações propostas pela Sociedade Brasileira de Computação, o ensino remoto requer o uso de ferramentas tecnológicas para disponibilização dos conteúdos e acompanhamento das atividades realizadas pelos estudantes ${ }^{1}$.

No ensino remoto são necessários novos olhares, pois existem características próprias. As três características nesse novo modelo de ensino que devem ser seguidas são a personalização, a colaboração e a tutoria [11]. Devemos levar em conta que cada aluno possui um ritmo de aprendizagem diferente e, neste cenário, um dos papéis do professor é ser mediador e tutor de suas turmas [11].

A aprendizagem passou a ser mediada pelas tecnologias, e muitos professores não estão preparados para trabalhar com essa nova maneira de ensinar, e têm que se reinventar para apoiar alunos e familiares. Não cabem mais as aulas expositivas, sendo necessário replanejar as atividades de

\footnotetext{
${ }^{1}$ Disponível em: http://www.sbc.org.br/noticias/2195-central-sbc-covid-19-material-de-apoio-as-atividades-a-dista Acesso em 29 jul. 2020.
} 
tal forma que o processo de ensino e aprendizagem envolva o pensamento crítico, autonomia e protagonismo do aluno.

Neste sentido, a convivência virtual torna-se tão importante quanto a presencial. Sabe-se que essa não é uma proposta fácil de implementação, visto o conservadorismo de algumas instituições de ensino, entretanto a busca de uma gestão flexível possibilita essa mudança de cenário [13].

A educação não pode ser um ato meramente digital, porém esse novo normal revelou um conjunto de problemas existentes há muito tempo: a escola não é inclusiva e não está preparada para atender alunos do século XXI, não é inspiradora e não dá espaço aos professores criadores e autônomos, que produzem currículos e não apenas aplicam.

Nessa transformação há uma diversidade de espaços, tempos e uma heterogeneidade de formas de ensino e aprendizagem que não existiam no modelo normal [18].

O professor então reinventa, inova, experimenta, troca conhecimentos, faz a mediação da aprendizagem através das tecnologias para atender todos os alunos com equidade, pois cada estudante é único e possui habilidades diferenciadas.

De acordo com Moran [15]:

As tecnologias ampliam as possibilidades de pesquisa on-line, de trazer materiais importantes e atualizados para o grupo, de comunicar-nos com outros professores, alunos e pessoas interessantes, de ser coautores, "remixadores" de conteúdos e de difundir nossos projetos e atividades, individuais, grupais e institucionais muito além das fronteiras físicas do prédio. (Moran, 2015, p. 25)

\subsection{Desenho Universal para a Aprendizagem (DUA)}

O modelo pedagógico do Desenho Universal para a Aprendizagem (DUA) engloba princípios e estratégias que permitem ao docente definir objetivos de ensino e criar materiais e formas de avaliação que se adequem a todos os alunos, de modo que todos possam aprender na via comum da educação [10]. O DUA é um modelo que surgiu a partir de estudos da Neurociência, cuja contribuição fundamental é compreender como o cérebro aprende e como ensinar de forma eficaz.

Neste sentido, a aprendizagem é um processo que envolve três grandes redes neurais: redes de reconhecimento (o "quê" da aprendizagem), redes de estratégia (o "como" da aprendizagem) e redes afetivas (o "porquê" da aprendizagem) [10]. Essas redes são apresentadas na Figura 1.

\begin{tabular}{|c|c|c|}
\hline $\begin{array}{c}\text { Redes Afetivas } \\
\text { (O porquê da } \\
\text { aprendizagem) }\end{array}$ & $\begin{array}{c}\text { Redes de Reconhecimento } \\
\text { (O quê da aprendizagem) }\end{array}$ & $\begin{array}{c}\text { Redes estratégicas } \\
\text { (O como da aprendizagem) }\end{array}$ \\
\hline $\begin{array}{c}\text {-Envolvimento: apresentar } \\
\text { o conteúdo utilizando } \\
\text { diversos meios que } \\
\text { motivem o aprendizado. }\end{array}$ & $\begin{array}{c}\text {-Representação: considera } \\
\text { os vávios estilos de } \\
\text { aprendizagem (auditivos, } \\
\text { visuaise sinestésicos) }\end{array}$ & $\begin{array}{c}\text {-Ação e expressão: } \\
\text { manifestação das } \\
\text { competências adquiridas. }\end{array}$ \\
\hline
\end{tabular}

Figura 1: Princípios do DUA. Adaptado de [10]. 
No primeiro princípio, "o porquê" - reconhecemos que os alunos diferem nos seus interesses e nas formas como podem ser envolvidos e motivados para aprender, "como os aprendizes se engajam e permanecem motivados. Como eles são desafiados, como se entusiasmam e se interessam" [23, p.21].

No segundo princípio, "o quê" - consideramos que os alunos diferem no modo como percebem e compreendem a informação que lhes é apresentada, como recolhemos fatos e categorizamos o que vemos, ouvimos e lemos. Identificar letras, palavras ou estilos de autores são tarefas de reconhecimento, referem-se ao princípio da representação. Quanto maiores as possibilidades de apresentar um novo conhecimento, maiores serão as possibilidades em aprendê-lo [27].

No terceiro princípio, "o como" - pressupomos que os alunos diferem no modo como podem participar nas situações de aprendizagem e expressar o que sabem [19].

A metodologia DUA vem ao encontro dos princípios de Educação Inclusiva, pois a elaboração de recursos, materiais, atividades e espaços educativos flexíveis para o aprendizado de todos os alunos contempla, assim, a diversidade, os diferentes estilos e ritmos de aprendizagem [27].

São muitos os fatores que influenciam a relação de ensino e aprendizagem, como os ambientais, físicos, emocionais, cognitivos, sociais, entre outros. Muitas também são as teorias acerca desse tema extremamente complexo: as metodologias de ensino e aprendizagem. Talvez, um dos poucos consensos é que cada indivíduo possui um ritmo e forma característica de aprender, daí surgem os chamados Estilos de Aprendizagem [25].

No ano de 1988, Felder e Silverman propuseram um modelo em que as preferências de cada aluno pudessem ser classificadas [6]. A seguir, a Figura 2 evidencia essas características.

\begin{tabular}{|c|c|c|}
\hline Dimensões & Polos & Preferências de aprendizagem \\
\hline \multirow[t]{2}{*}{ Percepção } & Sensorial & $\begin{array}{l}\text { Aprendem melhor através de } \\
\text { fatos, dados e experimentação. }\end{array}$ \\
\hline & Intuitivo & $\begin{array}{l}\text { Aprendem melhor através de } \\
\text { conceitos e teoria }\end{array}$ \\
\hline \multirow[t]{2}{*}{ Entrada } & Visuais & $\begin{array}{l}\text { Aprendem melhor com recursos } \\
\text { visuais, como imagens, } \\
\text { diagramas e demonstrações. }\end{array}$ \\
\hline & Verbais & $\begin{array}{l}\text { Aprendem melhor com } \\
\text { explicação verbal. }\end{array}$ \\
\hline \multirow[t]{2}{*}{ Processamento } & Ativos & $\begin{array}{l}\text { Compreendem de forma mais } \\
\text { fácil ao realizar experimentos. }\end{array}$ \\
\hline & Reflexivos & $\begin{array}{l}\text { Compreendem melhor conceitos } \\
\text { que os levem à reflexão. }\end{array}$ \\
\hline \multirow[t]{2}{*}{ Entendimento } & Sequenciais & $\begin{array}{l}\text { Possuem um raciocínio linear e } \\
\text { compreendem melhor conteúdos } \\
\text { de dificuldade gradual. }\end{array}$ \\
\hline & Globais & $\begin{array}{l}\text { Compreendem melhor conteúdos } \\
\text { vistos por saltos intuitivos. }\end{array}$ \\
\hline
\end{tabular}

Figura 2: Dimensões, Polos e características. Adaptado de [6]

Pensar em atividades com base nos polos e dimensões dos estilos de aprendizagem dos estudantes pode proporcionar um ótimo ambiente de aprendizagem para os alunos, porém, em tempos de pandemia torna-se mais difícil identificar os estilos ou dificuldades de aprendizagem; nesse sentido pensamos em atividades lúdicas que podem motivar os alunos utilizando as tecnologias. Dessa 
forma, [2]:

\begin{abstract}
Pode-se entender que na educação a teoria dos estilos de aprendizagem explica a importância da tecnologia como potencializadora de conteúdos para atender a diversidade de aprendizagens existentes. Essas aprendizagens são influenciadas não somente pelo formato das tecnologias, mas principalmente pelos novos referenciais que ela disponibiliza como a informação, a linguagem, a interatividade, a cibercultura e o virtual. (Barros, 2008, p. 24)
\end{abstract}

Com relação aos conhecimentos matemáticos, enfatizamos a necessidade de colaborar com a aprendizagem dos alunos voltada para o campo de suas ideias e seu cognitivo, fazendo com que os mesmos sejam agentes de sua construção do conhecimento. Assim, optamos por realizar as atividades com apoio da Matemática Recreativa.

\title{
2.3. A Matemática Recreativa
}

A Matemática Recreativa envolve um conjunto de problemas, métodos, resultados e ideias matemáticas que mobiliza tanto matemáticos profissionais como pessoas não especializadas que têm curiosidade e certo encanto pelos desafios, jogos, quebra-cabeças e uma diversidade de atividades que não tem outro objetivo que não o de entreter e desafiar. Essa metodologia é praticada por puro desejo e não necessariamente como uma atividade profissional. Seus problemas contribuem para desenvolver o raciocínio lógico, a intuição e a criatividade [8].

Os aspectos mais importantes da Matemática Recreativa são a imaginação e o engenho no desenvolvimento das atividades e sua utilização vai além do uso de jogos, visto que sua abrangência é vasta [22].

A Matemática Recreativa pode ser vista sob quatro abordagens e perspectivas: popular-científico (divertida a Matemática e popular), lúdico e de entretenimento (ser feliz enquanto se faz matemática), pedagógico (recurso didático) e histórico (responsável pela origem de conceitos e teorias). Quanto ao aspecto pedagógico, a Matemática Recreativa é um ótimo recurso de ensino, pois através dos jogos, adivinhações e quebra-cabeça, estamos proporcionando ao aluno a construção de conhecimentos matemáticos de suma importância, uma vez que "brincando" ele adquire habilidades para resolver diversos problemas, pois durante a atividade está buscando estratégias para a resolução, sem precisar seguir regras e fórmulas para a aprendizagem de conteúdos matemáticos $[5]$.

No âmbito da Matemática Recreativa estão inseridos os jogos que, de acordo com Vygotsky, propiciam o desenvolvimento da linguagem, do pensamento e da concentração. O lúdico influencia no desenvolvimento do aluno, ensinando-o a agir corretamente em uma determinada situação e estimulando sua capacidade de discernimento [20].

Um jogo matemático visa despertar o interesse e mobilizar a atividade do aluno na Matemática. Os jogos matemáticos aliam raciocínio, estratégia e reflexão, com desafio e competição, de uma forma lúdica. A sua prática contribui para o desenvolvimento da capacidade de formalização de estratégias, memorização e para o desenvolvimento pessoal e social [5].

Para Piaget, o jogo não deve ser realizado como apenas uma brincadeira, mas deve favorecer o raciocínio lógico, o desenvolvimento social, moral e cognitivo [21]. 
Para a realização das atividades escolhemos o Jogo Tangram, um quebra-cabeça formado por sete peças que tem formas geométricas bem conhecidas. São cinco triângulos, um quadrado e um paralelogramo, originados da decomposição de um quadrado maior. Sua idade e seu inventor são desconhecidos. Os chineses o conhecem por Tch'i Tch'iao pan, que significa "As sete tábuas da argúcia (habilidade, destreza)".

O Tangram possui um enorme apelo lúdico, pois oferece desafios a quem joga; ele serve como um material de apoio ao se trabalhar alguns conteúdos e conceitos matemáticos específicos ou até mesmo uma forma de propiciar o desenvolvimento de habilidades de pensamentos, quando, explorado em uma situação concreta, favorece o desenvolvimento intelectual do aluno[24]. Além disso,

Os benefícios de se jogar Tangram são maiores do que imaginamos. Este quebracabeça é capaz de estimular tanto a lado esquerdo do cérebro, que lida com a lógica, quanto o lado direito, que é encarregado das informações abstratas.

Exercita a resolução de problemas. Para montar cada figura é necessário planejar onde as peças serão colocadas;

Estimula a criatividade. As peças do jogo permitem que várias figuras sejam montadas, sendo que algumas dessas figuras podem ser montadas de maneiras distintas;

Melhora a noção espacial. O Tangram exige que peças sejam posicionadas e rotacionadas, levando o cérebro a trabalhar as regiões responsáveis pelo reconhecimento $e$ posicionamento de formas geométricas. [7] (Geniol, 2020, n.p)

Em termos pedagógicos, o Tangram pode ser utilizado no ensino de Geometria, exigindo somente imaginação, paciência, criatividade, e potencializa a realização de atividades de percepção visual no plano e a capacidade de ver as partes no todo [5].

Além disso, a utilização de jogos matemáticos tende a "diminuir bloqueios apresentados por muitos de nossos alunos que temem a Matemática e sentem-se incapacitados para aprendê-la" [4, p.9].

\section{Metodologia}

Este estudo é discutido por meio de uma pesquisa qualitativa. A abordagem qualitativa trabalha com o universo de significados, motivos, aspirações, crenças, valores e atitudes, o que corresponde a um espaço mais profundo das relações, dos processos e dos fenômenos que não podem ser reduzidos à operacionalização de variáveis [16].

Foi realizada uma entrevista, através de um questionário semiestruturado, com 57 professores, no qual os mesmos puderam relatar suas percepções sobre o Desenho Universal para a Aprendizagem.

Considerando os resultados obtidos, foram criadas diversas propostas de atividades baseadas nas possibilidades envolvidas no Tangram, tendo como ferramenta o DUA. Para a composição dessas atividades, foi elaborado um livro digital interativo, disponibilizado na plataforma on-line do Geogebra.

A seguir, mais detalhes serão evidenciados. 


\section{Resultados e discussões}

A fim de conhecer o perfil dos 57 professores entrevistados, tem-se a Figura 3

\begin{tabular}{|l|l|l|} 
Titulação & Tempo que leciona & Área de atuação \\
\hline Graduação (12) & 1 a 5 anos (7) & Educação Infantil (13) \\
\hline Pós-Graduação (31) & 5 a 10 anos (7) & Ensino Fundamental I (19) \\
\hline Mestrado (8) & 10 a 15 anos (10) & Ensino Fundamental II (27) \\
\hline Doutorado (6) & 15 a 20 anos (10) & Ensino Médio (20) \\
\hline & Mais de $20 \operatorname{anos}(23)$ & Ensino Superior (8) \\
\hline
\end{tabular}

Figura 3: Perfil dos participantes da pesquisa.

De acordo com a Figura 3, observa-se a titulação, a área da atuação e o tempo de atuação dos docentes entrevistados.

A entrevista teve como base quatro questões a fim de verificar se os docentes lecionam ou lecionaram em classes inclusivas, se têm formação específica para trabalhar com a inclusão, se conhecem e quais são as percepções sobre o Desenho Universal para a Aprendizagem. A seguir, observam-se algumas respostas representadas na Figura 4.

\begin{tabular}{|c|c|c|c|}
\hline $\begin{array}{l}\text { Você leciona } \\
\text { lecionou em } \\
\text { inclusivas? }\end{array}$ & $\begin{array}{c}\text { ou já } \\
\text { classes }\end{array}$ & $\begin{array}{l}\text { Você tem alguma } \\
\text { formação específica para } \\
\text { trabalhar com alunos de } \\
\text { inclusão? }\end{array}$ & $\begin{array}{llr}\text { Você conhece } & \text { o Desenho } \\
\text { Universal para } & \text { a } \\
\text { Aprendizagem (DUA) } & \end{array}$ \\
\hline $\operatorname{Sim}(50,9 \%)$ & & $\operatorname{Sim}(17,5 \%)$ & $\operatorname{Sim}(17,5 \%)$ \\
\hline Não $(49,1 \%)$ & & Não $(82,5 \%)$ & Não $(82,5 \%)$ \\
\hline
\end{tabular}

Figura 4: Perguntas da entrevista.

Notamos na verificação dos dados da Figura 4 que os professores que conhecem o Desenho Universal para a Aprendizagem são, percentualmente, os mesmos que têm formação específica para trabalhar com a inclusão. Além disso, observamos que $82,5 \%$ dos professores não conhecem os processos de ensino e aprendizagem com base no Desenho Universal para a Aprendizagem, que é uma forma de proporcionar flexibilização e participação de todos os estudantes, oferecendo maneiras diferenciadas para o desenvolvimento de conteúdo, respeitando seus estilos de aprendizagem (visuais auditivos e sinestésicos), podendo ser utilizado no ensino remoto, onde o professor não está presente fisicamente, mas continua com o papel de mediador com a utilização das tecnologias. A decisão de apresentar a mesma atividade de outra forma pode resultar no entendimento daquele aluno que não conseguia aprender e até contribuir para que outros alunos compreenderem melhor um determinado assunto [27].

Assim, o DUA pode ser visto como uma metodologia inclusiva, pois tem como objetivo a construção de práticas pedagógicas acessíveis para a aprendizagem de todos os alunos.

Na última pergunta da entrevista indagamos: Como você utiliza ou utilizou o DUA nas suas aulas? A seguir, segue a transcrição das respostas de três participantes. 
Proporcionando possibilidades que quebrem barreiras que estejam impedindo o estudante de realizar suas atividades escolares nessa perspectiva, cada caso deve ser pensado em sua individualidade. (Resposta obtida na entrevista)

O DUA é utilizado de maneira a beneficiar que todos os educandos possam acessar os currículos e seus conteúdos e conceitos de maneira equitativa. Levando-se em consideração as diversas formas de aprendizagem de uma sala de aula, se possibilita a quebra de barreiras por meio de didáticas, estratégias e práticas onde os saberes possam ser contemplados. Diversas vias de aprendizagens, instrumentais, tecnológicas, concretas, por imagens, textos e diálogos que estimulem tais diversidades de saberes. (Resposta obtida na entrevista)

Embora eu atue na educação especial, procuro estabelecer parceria com os professores das turmas regulares não somente para possibilitar a adaptação necessária para que os estudantes com deficiência participem das atividades propostas, mas para que as aulas contem com estratégias e materiais que contemplem a todos os estudantes em sua multiplicidade de características de aprendizagem. O principal tem sido o diálogo sobre os objetivos estabelecidos e os encaminhamentos para que os estudantes atinjam esses objetivos. (Resposta obtida na entrevista)

Esses relatos refletem a necessidade de meios diversificados para atender aos alunos, pois trazem conceitos importantes sobre a necessidade de pensar em estratégias e meios diversificados que auxiliem as especificidades do aluno, vindo ao encontro da perspectiva do Desenho Universal para a Aprendizagem DUA, no qual o mesmo material pode ser utilizado por todos da sala de aula, de modo a beneficiar outros estudantes na compreensão dos conteúdos ensinados [27].

Considerando os resultados obtidos, foi elaborado um livro digital interativo, disponibilizado na plataforma do Geogebra, com atividades baseadas nos recursos didáticos do Tangram, tendo como ferramenta o DUA, conforme representa a Figura 5. 


\begin{tabular}{|c|c|c|}
\hline PRINCÍPIO DUA & ESTRATÉGIA & ATIVIDADE PROPOSTA \\
\hline ENVOLVIMENTO & $\begin{array}{l}\text { Informação Visual e } \\
\text { Auditiva } \\
\text { Facilitar a capacidade } \\
\text { individual e superar } \\
\text { difículdades. } \\
\text { Ativar conhecimentos } \\
\text { prévios. } \\
\text { Motivação } \\
\text { Caráter lúdico }\end{array}$ & $\begin{array}{l}\text { Conhecendo o Tangram: } \\
\text { O quebra cabeça } \\
\text { História } \\
\text { Construção do Tangram de Papel } \\
\text { Brincando com o Tangram }\end{array}$ \\
\hline REPRESENTAÇÃO & $\begin{array}{l}\text { Vocabulário, linguagem, } \\
\text { símbolos. } \\
\text { Ilustrar utilizando } \\
\text { diferentes mídias. } \\
\text { Oferecer opções para as } \\
\text { funções executivas } \\
\text { (memória, raciocinio) } \\
\text { desenvolvimento de } \\
\text { estratégias. }\end{array}$ & $\begin{array}{l}\text { Reconhecer as formas geométricas do Tangram: } \\
\text { As formas geométricas } \\
\text { Composição de formas Investigando a área do } \\
\text { Tangram: } \\
\text { O quadradinho e o triângulo pequenos como } \\
\text { unidade de área (Explorar conceitos de área) } \\
\text { Frações no Tangram (explorar a equivalência) }\end{array}$ \\
\hline AÇÃO/EXPRESSÃO & $\begin{array}{l}\text { Desenvolver a auto- } \\
\text { avaliação. } \\
\text { Diversificar os meios de } \\
\text { resposta. }\end{array}$ & O que aprendi com o Tangram? \\
\hline
\end{tabular}

Figura 5: Atividades com o Tangram relacionadas com o DUA.

Nas próximas seções essa estratégia será detalhada.

\subsection{Proposta de atividade com o jogo Tangram}

O ensino remoto tem como uma de suas ferramentas as tecnologias. Nesse sentido, as atividades foram pensadas dentro desse contexto, com a utilização de recursos da internet, e do Geogebra. O Geogebra é um software de geometria dinâmica, gratuito, podendo ser instalado e acessado em computadores e dispositivos móveis, sendo de fácil manuseio, combinando geometria, álgebra, cálculo, estatística, facilitando a aprendizagem de maneira eficaz [17]. Ao utilizar e explorar construções realizadas no software, o aluno constrói suas hipóteses e tenta validar as propriedades dentro do conteúdo proposto, assim [28]:

O próprio aluno irá realizar a verificação e validação da conjectura que formulou. Isso é possível devido aos recursos dos softwares, como o arrastar, que possibilita a simulação de diferentes casos da figura, como se o aluno estivesse verificando "todos" os casos possíveis de uma mesma família de configuração. (Zulatto, 2002, p.21)

Dessa forma, para tal proposta de ensino remoto, foi elaborado um livro digital interativo, baseado no DUA, composto por atividades que envolvem o Tangram. Esse livro interativo foi elaborado 
dentro da plataforma do Geogebra devido à possibilidade de manipulação das figuras e preenchimento de respostas on-line. A seguir apresentamos as atividades que compõem o livro Atividades com o Tangram, disponível em http://www.geogebra.org/m/ycuwva2b, que tem como objetivo explorar alguns conceitos de geometria com a utilização do Tangram. A Figura 6 evidencia a tela principal do livro digital.

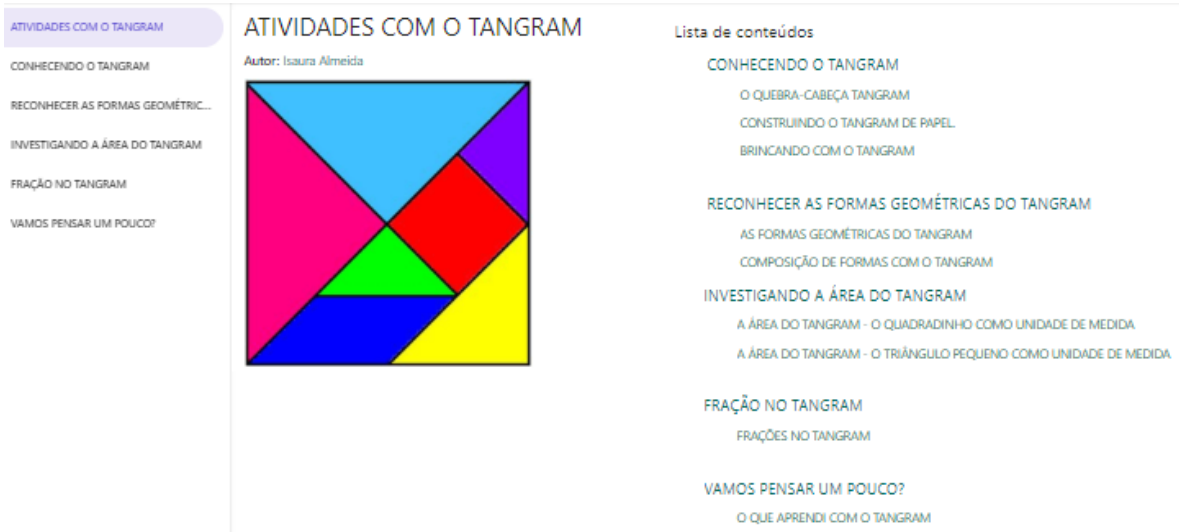

Figura 6: Tela principal do livro interativo digital elaborado.

Considerando a Figura 6, à esquerda temos as seções do livro e à direita temos o sumário com as seções e subseções. Ao clicar sobre uma seção ou subseção do livro de atividades, uma nova página é aberta e nela haverá vídeos explicativos, textos, atividades de manipulação das figuras do tangram em $2 \mathrm{D}$ e atividades de raciocínio lógico a serem respondidas pelos usuários. A seguir, os itens do sumário serão detalhados:

\section{Conhecendo o Tangram}

- O Quebra-cabeça Tangram: O objetivo desta atividade é que os alunos conheçam algumas características do jogo e sua lenda, que, pelo desenvolvimento do vídeo, traz a história com figuras compostas pelo jogo, despertando assim motivação para a aprendizagem. Para Moran: o vídeo combina a comunicação sensorial-cinética, com a audiovisual, a intuição com a lógica, a emoção com a razão. Combina, mas começa pelo sensorial, pelo emocional e pelo intuitivo, para atingir posteriormente o racional [12].

- Construindo o Tangram de Papel: Nesta atividade os alunos são convidados a assistir como se realiza a construção do Tangram de papel, bem como realizar a construção do mesmo, seguindo com a composição de algumas formas geométricas com as peças do jogo.

- Brincando com o Tangram: Para tornar o aprendizado mais interessante os alunos vão construir uma das figuras disponibilizadas no software Geogebra, dando um caráter lúdico para a atividade.

2. Reconhecer as formas geométricas do Tangram. 
- As formas geométricas do Tangram: Apresentamos através de imagem as peças que compõem o Tangram, como representado na Figura 7, e elaboramos algumas questões (como: quantos triângulos existem no Tangram?; Escreva um pequeno texto descrevendo o paralelogramo de modo que possamos identificar a peça a partir da descrição) a fim de que os alunos observassem características das mesmas e respondessem de forma dissertativa.

\section{AS FORMAS GEOMÉTRICAS DO TANGRAM}

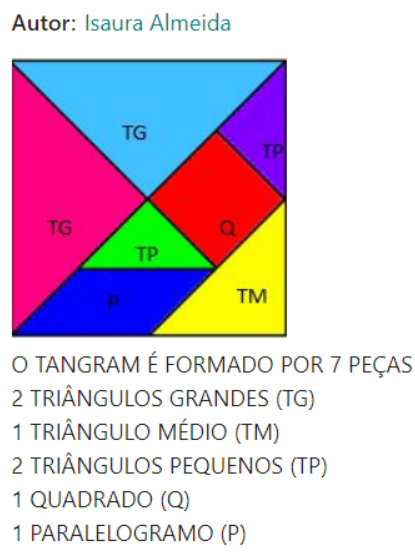

Figura 7: As formas geométricas do Tangram.

- Composição de formas com o Tangram: Inserimos o vídeo "Super Mário Tangram" 2, para que os alunos visualizassem como a paisagem contêm várias formas compostas pelas peças do jogo. A seguir com o auxílio do Applet (ferramenta do Geogebra) solicitamos que o usuário respondesse as questões relacionadas a composição de formas, sendo elas:

Com quais peças podemos cobrir o quadrado maior?

Com quais peças podemos cobrir o paralelogramo?

Com quais peças podemos cobrir o triângulo grande?

Com três pelas monte um quadrado. Quais peças você usou?

Com quais peças podemos formar uma figura equivalente aos dois triângulos grandes?

3. Investigando a área do Tangram

- A área do Tangram - o quadradinho como unidade de medida.

- A área do Tangram - o triângulo pequeno como unidade de medida.

Essas atividades têm como objetivo a compreensão de área utilizando unidades diferenciadas: o quadradinho da malha e o triângulo pequeno. Utilizando a "movimentação" dos objetos (quadradinho e triângulo pequeno), os alunos podem observar e analisar as atividades, interpretando os resultados através da visualização, como representa Figura 8.

\footnotetext{
${ }^{2}$ Disponível em: http://www.youtube.com/watch?v=_uKWsqoJ8Ss. Acesso em 29 jul. 2020.
} 

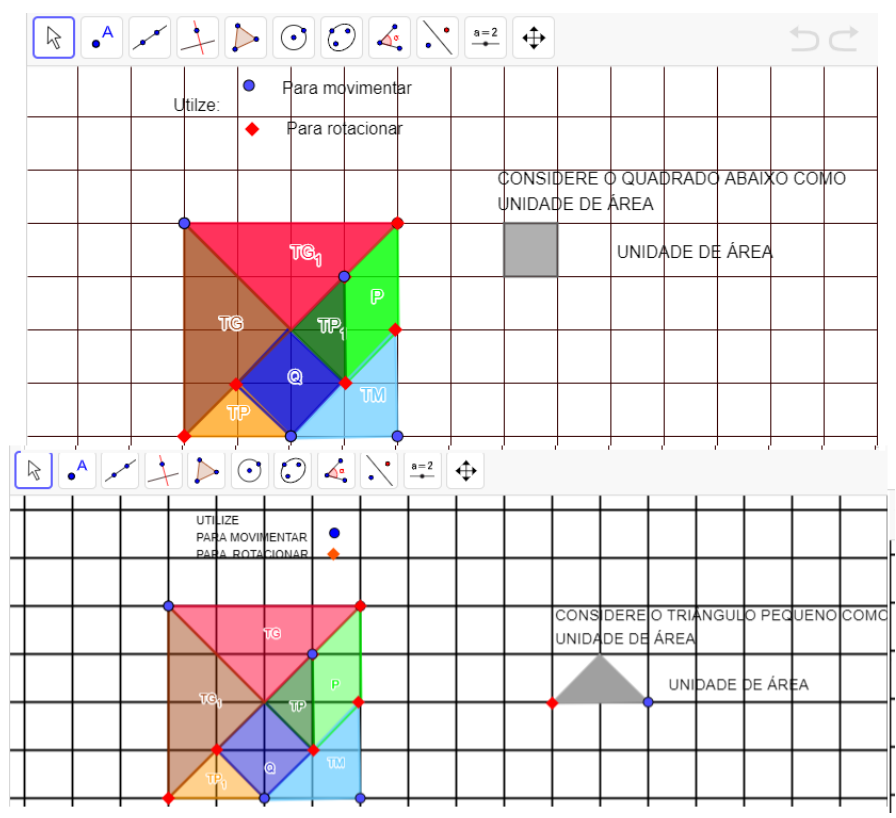

Figura 8: As unidades de medidas adotadas.

\section{Frações no Tangram}

- Frações: Nesta seção o usuário tem a opção de manipular as peças do Tangram para obter noções de comparação e equivalência. A abordagem de frações com o uso do triângulo pequeno para comparar as outras peças proporciona a compreensão de alguns conceitos como partetodo. Com a possibilidade da movimentação do triângulo pequeno, por exemplo, no caso do quadrado, pode ser concluído que a fração corresponde a 2 triângulos pequenos, construindo dessa forma a ideia de equivalência de forma lúdica, como representado pela Figura 9. 


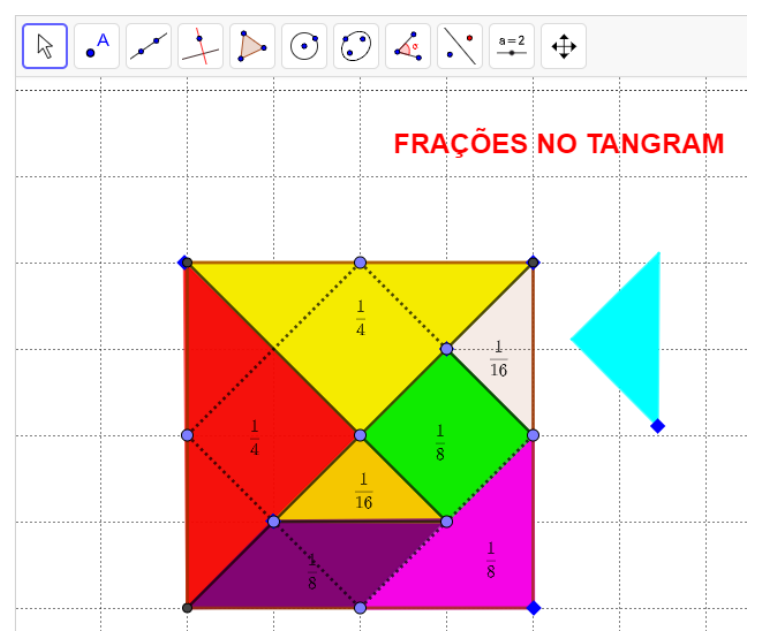

Figura 9: Frações no Tangram.

Após realizar as manipulações, sugerimos que o usuário responda algumas questões no livro interativo, a fim de concluir os conceitos:

O paralelogramo que fração representa?

O triângulo médio que fração representa?

O triângulo grande que fração representa?

Quais peças representam metade do Tangram?

5. Vamos pensar um pouco?

- O que eu aprendi com o Tangram?: Para finalizar as atividades propusemos questões sobre assuntos trabalhados nas atividades anteriores, bem como demos espaço para que o aluno registre o que aprendeu. Esse tópico trata-se de um questionário com correção automática em que o usuário poderá verificar sua resposta.

Consideramos que o livro de atividades elaborado como forma de promover o DUA e a Matemática Recreativa em tempos de pandemia possui grande potencial de ensino. Como o livro foi criado na plataforma do Geogebra, o usuário poderá escolher realizar as leituras, atividades e até mesmo as manipulações, através do computador ou do próprio aparelho de celular, tornando o conteúdo acessível.

\section{Conclusão}

Diante deste "novo normal" percebemos que o ensino não é (e não será) mais o mesmo. Frente a esse novo cenário o professor precisa reformular suas práticas para que suas aulas contribuam para a aprendizagem dos alunos, tendo como suporte as tecnologias. Uma das maneiras de proporcionar essa aprendizagem de forma lúdica é através dos jogos. A utilização do quebra-cabeça Tangram, com base no Desenho Universal para a Aprendizagem e da Matemática Recreativa, pode fazer com que os alunos tenham maior interesse em aprender, bem como pode contribuir para o 
desenvolvimento do raciocínio lógico e geométrico do estudante. De encontro aos princípios do Desenho Universal para a Aprendizagem, as atividades com o Tangram como recurso didático são apresentadas de formas variadas com recursos diversificados (vídeo, texto, imagem) e com suporte do software Geogebra que pela sua dinâmica vem ao encontro do interesse do aluno, enquanto sujeito ativo, pois oferece a análise de conceitos matemáticos e geométricos mediante a visualização e a interatividade, além de aumentar o interesse pela aprendizagem.

\section{Referências}

[1] Alves, L. Educação a distância: conceitos e história no Brasil e no mundo. Associação Brasileira de Educação a Distância, v. 10, pp. 83-92, 2011.

[2] Barros, D. M. V. "A teoria dos Estilos de Aprendizagem: convergência com as tecnologias digitais." Revista SER, Agudos/SP, v. 1, n. 2, 2008.

[3] Brasil. Lei de Diretrizes e Bases da Educação Nacional. Lei número 9394, 20 de dezembro de 1996. Estabelece as diretrizes e bases da educação nacional, 1996.

[4] Borin, J. Jogos e resolução de problemas: uma estratégia para as aulas de matemática. São Paulo: IME-USP; 1996.

[5] Costa, O. A matemática recreativa no ensino Básico. Dissertação (Mestrado em Ciências), Universidade do Minho, Escola de Ciências, Braga, Portugal, 2014.

[6] Felder, R. M; Silverman, L. K. "Learning and teaching styles in engineering education. Learning and teaching styles in engineering education." Engineering Education, v. 78, n. 7, pp. 674-681, 1988.

[7] Geniol. Tangram, 2020. Disponível em: http://www.geniol.com.br/raciocinio/tangram/. Acesso em 29 jul. 2020.

[8] Lopes, A. J. Reflexões de um educador matemático. São Paulo, 2015. Disponível em: http://www.youtube.com/watch?v=GTTgq5HcAuY. Acesso em 25 jun. 2020.

[9] Mantoan, M. T. E.Inclusão Escolar:o que é? Por quê? como fazer? São Paulo: Moderna, 2003.

[10] Meyer, A.; Rose, D. H.; Gordon, D. Universal Design for Learning: Theory \& Practice. [s.l.]: CAST Professional Publishing, 2014.

[11] Moran, J. M. Entrevista: o papel do professor na aprendizagem ativa. Disponível em: http://box.novaescola.org.br/etapa/3/educacao-fundamental-2/caixa/96/inverta-asala-de-aula-durante-a-quarentena/conteudo/19021. Acesso em 29 jul. 2020.

[12] Moran, J. M. Leituras dos Meios de Comunicação. São Paulo: Pancast, 1993.

[13] Moran, J. M.; Masetto, M. T.; Behrens, M. A. Novas Tecnologias e Mediação Pedagógica. 21 ed. Campinas: Papirus, 2013.

[14] Moran, J. M.; Masetto, M. T.; Behrens, M. A. Novas Tecnologias e Mediação Pedagógica. 21 ed. Campinas: Papirus, 2013.

[15] Moran, J. M. Mudando a educação com metodologias ativas. Coleção mídias contemporâneas. Convergências midiáticas, educação e cidadania: aproximações jovens, v. 2, n. 1, pp. 15-33, 2015.

[16] Minayo, M. C. S. Pesquisa Social.(org.) Pesquisa Social. Teoria, método e criatividade. 18 ed. Petrópolis: Vozes, 2001.

[17] Nascimento, D. L. et al. "Minicurso: construções de triângulos através do software geogebra". Forscience, Formiga, v. 5, n. 3, 2017. 
[18] Nóvoa, A. Webconferência Prof. António Nóvoa. Disponível em https://www.youtube.com/watch?v=ef3YQcbERiM. Acesso em 29 mar. 2020.

[19] Nunes, C.; Madureira, I. "Desenho Universal para a Aprendizagem: Construindo práticas pedagógicas inclusivas". Da Investigação às Práticas, v. 5, n. 2, pp. 126-143, 2015.

[20] Oliveira, M. K. Vygotsky: Aprendizado e desenvolvimento um processo sócio-histórico. São Paulo: Scipione, 2002.

[21] Piaget, J. A psicologia da inteligência. Lisboa: Editora Fundo de Cultura S/A, 1967.

[22] Santos, C. P. Martin Gardner e a celebração da mente. Portugal, 2014. Disponível em http://wsimag.com/pt/ciencia-e-tecnologia/11362-martin-gardner-e-a-celebracao-da-mente. Acesso em 29 jul. 2020.

[23] Santos, M. P. dos. Desenho Universal para a Aprendizagem. Dislexia - Novos temas Novas perspectivas. Rio de Janeiro: WAK, 2015.

[24] Souza, E. R. et al. A Matemática das sete peças do Tangram. São Paulo: CAEM/IME-USP, 2008. 102p.

[25] Vieira Junior, N. Metodologias de Ensino e Aprendizagem. Arcos: IFMG, 2019.

[26] Unesco. Impacto da Covid-19 na educação. Disponível em: http://pt.unesco.org/covid19/educationresponse. Acesso em 25 jun. 2020.

[27] Zerbato, A. P.; Mendes, E. G. "Desenho universal para a aprendizagem como estratégia de inclusão escolar". Revista Educação da UNISINOS, v. 22, pp. 147-155, 2018.

[28] Zulatto, R. B. A. Professores de matemática que utilizam softwares de geometria dinâmica: suas características e perspectivas. 184f. Dissertação (Mestrado em Educação Matemática) Instituto de Geociências e Ciências Exatas, Universidade Estadual Paulista, Rio Claro, 2002.

Isaura Aparecida Torse de Almeida Instituto Federal de Educação Ciência e Tecnologia de Minas Gerais - campus Arcos <maeiata@gmail.com>

Dandara Lorrayne do Nascimento Instituto Federal de Educação Ciência e Tecnologia de Minas Gerais - campus Arcos <dandaralno@gmail.com>

Recebido: $30 / 07 / 2020$

Publicado: 02/02/2021

Chamada Temática "Experiências didáticas em Matemática no período de isolamento social" 